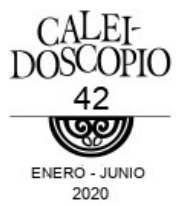

\title{
La falsa realidad. Reflexiones sobre la representación
}

The fake reality. Reflections on representation

LUCÍA CASTAÑEDA GARMA

Universidad de las Artes, México

\section{RESUMEN}

A partir de recuerdos personales se desarrolla una serie de reflexiones acerca del concepto de representación y su relación con la realidad, basadas en autores que han estudiado la imagen. El planteamiento enfatiza en la fotografía como la disciplina que mejor ejemplifica dicha relación, pero que a la vez es la que cuestiona con mayor fuerza la idea de semejanza a través del recurso del artificio. El hilo conductor del texto es el animal, motivo central de la producción fotográfica que origina la presente investigación.

Palabras clave: realidad; representación; semejanza; fotografía; artificialidad.

\section{ABSTRACT}

Personal memories give rise to a reflection on the concept of representation and its relation to reality, based on authors who have studied the image. The approach emphasizes photography as the discipline that best exemplifies this relationship, but at the same time it is the one that most strongly questions the idea of similarity through the use of artifice. The main thread of the text is the animal, theme of 
the photographic work that originates the present investigation.

Keywords: reality; representation; similarity; photography; artificiality.

Cuando era niña me encantaba ver los libros de animales que había en la casa, podía hojearlos constantemente sin aburrirme de ellos. En las páginas de The love of baby animals, Atlas del mundo animal y Maravillas y misterios del reino animal encontraba un espacio ideal para entretenerme pensando en la vida y en el nombre que tendrían esos animales, inventando historias que relacionaban al oso panda que aparecía en un libro con el que estaba en el otro libro y con el que un día había visto en el zoológico, a veces los dibujaba en mi cuaderno y otras veces dibujaba sobre ellos; las páginas dobladas y rotas eran la prueba que desde muy pequeña estuve en contacto con esos libros. Pero el juego no se limitaba a esas páginas, la mayoría de mis juguetes eran animales de peluche así que verlos representados en los libros era una forma de saber más de ellos, de cómo eran sus familias y los lugares en los que vivían. Esa conexión de alguna manera me daba la certeza de que mis peluches eran "reales", lo cual me producía una gran felicidad.

Las fotografías que ilustraban esos libros fueron el detonante para que mi imaginación infantil creara una serie de fantasías que me mantuvieron ocupada durante años, asimismo el koala, el tucán y el perro de peluche, entre otros animales que tenía, fueron parte de los mundos de ficción y realidad entre los que alterné en mi infancia, como seguramente sucede con todos los niños y sus juguetes $u$ objetos favoritos. 
Esa alternancia, que es natural en ciertas etapas del crecimiento de una persona, la podemos encontrar también en otros ámbitos relacionados a la imaginación y a la representación del mundo real. Claramente, el arte es uno de ellos; a lo largo de la historia podemos encontrar ejemplos en la literatura, en el teatro, en el cine y por supuesto en las artes visuales, en que la realidad y la ficción se entremezclan para crear cierto tipo de obras. "Que el arte ama la realidad como tema es tan evidente como que igualmente usa la fantasía. También que las mezcla. Sabemos que existe tanto una ficción con visos de realidad como una no ficción que parece más fantástica que lo que cualquier imaginación pueda soñar" (Sainz, 2008, p. 175). Claro, a diferencia de lo que sucede en los juegos infantiles, en el arte, tanto en su producción como en su estudio, hay una reflexión consciente sobre la representación de esa realidad o esa ficción sobre las cuales se construye la obra.

Este tema probablemente sea una de las cuestiones sobre las que más han elucubrado los artistas visuales y los teóricos del arte de todas las épocas debido a que siempre ha habido un interés por plasmar tal cual lo que vemos en el mundo real. Como menciona César González Ochoa, el hecho de que se da por entendido que la vista es el sentido que nos permite percibir el mundo con mayor exactitud y precisión, y por tanto organizar la realidad que vemos y las imágenes que hemos ido almacenado a través de esa percepción visual (González Ochoa, 2005), puede ser la principal razón por la que tradicionalmente se ha buscado que la representación de la realidad se vea como la realidad misma.

Ernst Gombrich dedicó gran parte de sus reflexiones a analizar el problema de la representación, en uno de sus ensayos, Meditaciones sobre un caballo de juguete, parte precisamente del fenómeno que se da cuando un niño para 
jugar, asume que su caballo de madera -un palo de escoba cuyo remate tiene la forma burda de la cabeza de dicho animal- es efectivamente un caballo. Para empezar Gombrich cuestiona la idea generalizada acerca de que la imagen que representa a un objeto real tiene que ser una copia fiel que debe de imitar su aspecto externo para que pueda ser reconocida a pesar de que tenga cierto grado de abstracción. En el caballo de juguete no hay una fidelidad con respecto al animal que representa, "El palo no es un signo que signifique el concepto 'caballo', ni es un retrato de un caballo individualizado. Por su capacidad para servir como 'sustitutivo', el palo se convierte en caballo por derecho propio" (Gombrich, 2008, p. 2). Es decir, el palo tiene ciertas características mínimas que permiten que el niño se monte sobre él y lo cabalgue, sustituyendo la función que cumpliría el caballo real sin importar que su aspecto sea muy distinto al del original.

Si bien la representación "se trata de un proceso por medio del cual se intuye un representante que, en cierto contexto, ocupa el lugar de lo que representa" (González, 2005, p. 31), el deseo de otorgarle un parecido más cercano a su forma externa, más allá de que esté cumpliendo con la función básica de lo que representa, siempre está presente. Si al caballo de palo se le pintan unos ojos, se le agrega una crin y se le ponen riendas, no sólo servirá para montarlo sino que también será más fácilmente identificable como un caballo. El juguete que lleva a Gombrich a toda esta serie de reflexiones es ilustrado en su ensayo mediante un grabado del siglo XIV en el que varios niños retozan acompañados de varios objetos, lo que nos habla de la antigüedad de los caballos de palo; a la fecha esos juguetes siguen vigentes, menos rústicos que entonces, y fueron el origen de otras variantes como los balancines de madera a los que se les agregaron cola, patas y un cuerpo sobre el cual sentarse. 
Actualmente en los centros comerciales podemos ver que los caballitos además de tener la forma claramente definida, también están forrados con un peluche que asemeja el color y la suavidad de la piel del animal, y tienen un sistema de ruedas que permite que los niños se impulsen y "cabalguen". La función sigue siendo la misma, pero la representación se acercó más a su referente.

Se podría decir que desde siempre ha habido ¿un gusto, un deseo, una necesidad? por imitar, sobre todo, el aspecto externo de lo que se quiere representar. Seguimos considerando que una imagen es exitosa en la medida que la identificamos como "igual" a lo que representa. Por supuesto que esta actitud simplista ante la imagen se da con mayor frecuencia en la vida cotidiana, cuando no hay necesidad de analizar el problema más profundo que significa la representación; desde encargarle un retrato de nuestro ser querido a un dibujante técnicamente virtuoso porque el parecido con la persona va a ser idéntico hasta comprar una chamarra imitación piel porque se ve igual a las de piel auténtica y además es más económica.

Para González Ochoa "El problema fundamental de la representación se puede concentrar en el de las relaciones entre el mundo y la imagen, entre el objeto representado y el objeto que representa" (González, 2005, p. 37). Y como en cualquier otra situación, las relaciones que se establecen entre ambas partes pueden ser muy complejas, variables y difíciles de descifrar a pesar de su aparente sencillez. Es así que una de las relaciones se generan específicamente cuando hay una búsqueda de similitud, es la de la mímesis.

Este concepto se ha estudiado desde la Antigua Grecia; a lo largo de los siglos muchos pensadores han reflexionado sobre él desde diversas ópticas, abonando o cuestionando lo ya dicho por sus antecesores pero siempre pensando en 
la imagen representada como parte fundamental del desarrollo del arte y de la comunicación humana.

Uno de los primeros textos que se conocen al respecto es La Poética de Aristóteles. Virginia Aspe Armella hace un análisis de esta obra en la que explica que la mímesis no consiste únicamente en la imitación de modelos, sino en la generación de operaciones similares a las de la naturaleza: "sostenemos que la mímesis tiene por objeto la función de la naturaleza; esta dimensión es extracognitiva, pues no mira objetos, reproduce funciones" (Aspe, 2005). De acuerdo con esta concepción, coincidente con la idea ya mencionada de Gombrich, lo importante es que se reproduzca la manera en que algo funciona en la naturaleza, por ejemplo los estudios de Leonardo da Vinci sobre el vuelo de las aves derivaron en posibles artefactos que le permitirían al hombre volar, es decir, los aparatos mecánicos que diseñó eran una mímesis de los pájaros, tenían alas pero no eran una copia fiel de ellos, solamente imitaban los movimientos que él había observado que eran necesarios para ejercer el vuelo.

El interés por hacer las cosas de manera semejante a como se producen en la naturaleza ha sido llevado a muchos campos, otro caso es la relación existente entre la cámara fotográfica y el ojo. Cuando se trata de explicar cuáles son los fundamentos básicos para que una cámara registre una imagen, inmediatamente se hace una comparación con la manera en que las imágenes se forman dentro del ojo; este tema se desarrollará más adelante pero en este punto es útil mencionarlo como ejemplo de esa idea de mímesis que planteó Aristóteles, sobre todo porque además la cámara es un importante instrumento para llevar a cabo la representación.

En La Poética hay una sección que aborda el tema de las artes gráficas donde se refiere a la representación de imágenes. Aspe Armella comenta al respecto: 
(...) nos parece crucial para el significado de la mímesis pues indica "hacer ver", "activar", "presentar" algo como punto de partida -gestara través de los modelos. Aristóteles indica con ello que la tarea del arte es "formar una imagen" en donde no se trata sólo de copiar una imagen, en sentido reflejo del modelo, sino en el sentido en que la imagen produce tipos o modelos (Aspe, 2005, p. 209).

Sin embargo, con el paso del tiempo el término mímesis se extendió en el común de la gente manteniendo únicamente su acepción de imitación en el sentido de copia literal, al parecer se dio una especie de fusión con el concepto de mimetizar (RAE, 2014), por lo que si a alguien se le pregunta qué entiende por mímesis probablemente pensará en el proceso que realizan los camaleones para mimetizarse y verse iguales que su ambiente inmediato.

Otro concepto que está muy ligado a la representación y que sí tiene relación con el parecido externo del objeto representado, es la semejanza. De manera similar a la situación planteada con anterioridad, comúnmente se asume que la semejanza es el factor determinante del acto de representar, sin ella la representación no es efectiva. Pero a los ojos de filósofos como Nelson Goodman y Max Black, no es más que un componente del amplio problema de la representación.

Para Goodman la teoría de que la representación es una copia no es válida porque no se puede especificar cuál de los múltiples aspectos del objeto es el que se debe copiar; además de que el ojo, aun cuando se piensa que es el que puede captar con mayor precisión la realidad, no es objetivo ni autónomo, está condicionado por una serie de prejuicios y conocimientos que harán que automáticamente interprete de cierta manera lo que está percibiendo. 
De hecho hay algo que falla en la idea misma de copiar cualquiera de las formas de ser de un objeto, cualquier aspecto de él. Porque un aspecto del objeto no es simplemente el objeto-desde-unadistancia-una-luz-y-un-ángulo-determinados: se trata del objeto tal y como lo vemos o lo concebimos, es decir, de una versión o interpretación del mismo. Al representar un objeto, no copiamos dicha interpretación: la consumamos (Goodman, 2010, p. 24).

Una de las condiciones que Goodman considera necesarias para la representación es que denote algo, que se refiera al objeto al que se representa sin importar si tiene semejanza con él o no. Como ejemplo pone el cuadro de un unicornio; al verlo nos refiere a ese animal mítico, está representado ahí pero en realidad no representa nada porque el unicornio no existe y por lo tanto no se puede pensar en la semejanza porque no se parece a nada. Aquí es donde cobra más sentido la idea de la representación como "una relación simbólica, relativa y variable" (Goodman, 2010, p. 52) con el objeto, en la que hay una interpretación del mundo real o, como en el caso del unicornio, de una figura ficticia.

Max Black entiende la representación como un concepto-grupo, en el que un cuerpo de conocimientos "forman un entramado donde ninguno de ellos puede considerarse por separado como necesario o suficiente, pero todos ellos son pertinentes en el sentido de servir potencialmente para una aplicación idónea del concepto de representación figurativa" (Gombrich, Hochberg y Black, 1973, p. 167). Los componentes que destaca son el esquema de representación utilizado, la intencionalidad del autor y la semejanza. Explica que, por ejemplo, la comprensión de una representación fotográfica estará relacionada con el conocimiento que tengamos del proceso con el cual fue realizada, si sabemos qué es lo que el autor quería lograr y si reconocemos lo que vemos en la imagen porque se 
parece a algo; sin embargo ninguna de estas partes es indispensable para definir la representación: si vemos una fotografía de un animal y lo reconocemos es porque indudablemente estamos encontrando una semejanza, sin importar si desconocemos el origen de cómo fue tomada o si el fotógrafo tuvo la intención de mostrarlo así; o bien, si el animal no es semejante al original porque aparece muy movido en la foto pero conocemos la técnica con que fue realizada y sabemos que el autor quizo capturarlo de esa manera, también seremos capaces de comprender la representación que estamos viendo.

En suma, hay muchos argumentos para descartar la idea generalizada de que la representación es únicamente una copia; como dice González Ochoa, "producir un signo representativo es materializar un punto de vista, que necesariamente incluye el juicio valorativo, lo cual equivale a distinguir el objeto figurativo del objeto del mundo" (González Ochoa, 2005, p. 78). La representación denota a un objeto al que sustituye, su grado de semejanza es variable y en su construcción y significación están implicados la técnica utilizada y la intencionalidad e interpretación que haga del objeto el productor de dicha representación.

Hay cierto tipo de representaciones en las que ésta concepción ya se ha dado por entendida. En la pintura no se espera que las mujeres pintadas por Picasso en su período cubista sean iguales que las mujeres que representan, ni siquiera se espera que sean reales (Gombrich, Hochberg y Black, 1973, pp. 153-154), pero en otros campos, particularmente en la fotografía, la tendencia general sigue siendo la de creer que lo que representa es verdadero y que es una transcripción de la realidad, aún cuando en el mismo uso cotidiano de aplicaciones para modificar las imágenes capturadas con un teléfono haya una evidencia de que no es así. 
En su reconocido ensayo Sobre la fotografía, Susan Sontag afirma que "La fotografía tiene la deslucida reputación de ser la más realista, y por ende la más hacedera, de las artes miméticas" (Sontag, 2006, p. 79). ¿Pero cómo se comenzó a crear esa reputación? Tal vez habría que retomar los planteamientos originales sobre la mímesis como reproducción de las funciones de la naturaleza.

Desde Aristóteles es conocido el fenómeno natural de la cámara oscura; el cual se produce cuando en una habitación cerrada a la que no entra luz más que por un pequeño orificio en alguna de sus paredes, se forma una imagen del exterior en la pared opuesta de donde está esa mínima entrada de luz (Costa, 2008, p. 28). La imagen que proviene de la realidad exterior se proyecta invertida, de manera similar a como se crean las imágenes dentro de nuestros ojos.

Sin duda el funcionamiento del ojo humano es mucho más complejo que lo que sucede en la cámara oscura y en cualquiera de las cámaras fotográficas que han existido, desde las primeras que fueron utilizadas para la creación de daguerrotipos hasta las cámaras digitales de última generación; pero la construcción y perfeccionamiento de estos aparatos tiene similitudes básicas con la forma en que está constituido el ojo y, por lo tanto, en la forma que vemos.

La luz, que será la que proyectará la imagen invertida del exterior dentro del ojo/cámara, entra a través de un orificio, la pupila/diafragma, que se abre o cierra según sea la cantidad de luz en el ambiente. Pasará a través de un cristalino/lente que enfocará la imagen que será registrada por la retina/material fotosensible (Wright, 2001, p. 21). El funcionamiento de la cámara es pues, una mímesis del ojo en un sentido dinámico y de capacidad activa como el que decía Aristóteles. 
Más allá de tener conocimientos técnicos detallados sobre la formación, captura y procesamiento de las imágenes, desde el surgimiento de la fotografía creímos ingenuamente que ver y fotografiar son prácticamente lo mismo; como si la cámara fuera una extensión de nuestros ojos que lo único que hace es trasladar lo que vemos a un soporte fijo. Inclusive, en años recientes grandes empresas de tecnología han tratado de concretar esto mediante la invención de dispositivos como gafas y lentes de contacto que le permitan al usuario tomar fotografías y grabar video con tan solo un pestañeo.

Pero esa expresión de que la cámara ve tiene también un sentido literal, ya no metafórico: se trata de la idea de que la cámara da una imagen del mundo, es decir, una imagen de escenas, personas, objetos y acontecimientos, los cuales representan lo que veríamos si estuviéramos en el lugar de la cámara. En este sentido, se asume la imagen fotográfica como si fuera la forma en que se ven las cosas aunque nadie las esté viendo. Esta "forma en que las cosas se ven", se asume como si fuera una propiedad objetiva del mundo visual, que sólo espera ser recogida por un ojo (González, 2005, p. 19).

Parafraseando a Mallarmé, Sontag afirma que "Hoy todo existe para culminar en una fotografia" (Sontag, 2006, p. 44), pareciera que todo ha sido fotografiado y que las imágenes son las que nos permiten aprehender al mundo. Creemos que a través de las fotografías conocemos las cosas, los lugares y las personas porque son una huella y un reflejo de su existencia.

Philippe Dubois explica que a lo largo de su historia la fotografía ha sido comprendida de tres formas en cuanto a su relación con la realidad: (1) como espejo de lo real: se cree que lo que vemos en las imágenes es exactamente igual a su referente por el alto grado de semejanza que presenta; (2) como transformación de lo real: no se hace una copia de la 
realidad, sino una interpretación que está condicionada por el código fotográfico que suministra la cámara y por la subjetividad del fotógrafo; y (3) como huella de lo real: tal vez el objeto que vemos en la imagen no se parece a la realidad, pero no deja de tener su referente en ella porque de ahí fue tomado (Dubois, 1986, pp. 20-21).

Así pues, la representación fotográfica no solamente tiene la carga de la semejanza, sino que por ser una huella de lo real también arrastra con la consigna de la verdad: si lo que vemos en una foto es un reflejo de la realidad, por lo tanto es verdadero y tiene credibilidad. Dubois considera que el hecho de que exista un aparato mecánico de por medio es lo que le ha dado su carácter de testimonio fiel; eso que llama automatismo de su génesis técnica ha generado la percepción de que la fotografía es una prueba indudable.

Pero tal como sucede en la representación, que tiene un factor interpretativo por parte de quien la realiza, "La caja oscura fotográfica no es un agente reproductor neutro sino una máquina que produce efectos deliberados" (Dubois, 1986, p. 37). Dubois cita a Pierre Bourdieu quien cuestiona la objetividad de la fotografía porque por medio de la cámara, que tiene un punto de vista específico, se hace una selección concreta de la realidad que sólo puede capturar ciertos aspectos que se dieron en ese instante:

Dicho en otras palabras, la fotografía es un sistema convencional que expresa el espacio de acuerdo con las leyes de la perspectiva (habría que decir: de una perspectiva) y los volúmenes y los colores mediante gradaciones que van del negro al blanco. Si la fotografía se considera un registro perfectamente realista y objetivo del mundo visible es porque se le ha atribuido (desde su origen) usos sociales considerados "realistas" y "objetivos". Y si, inmediatamente, se ha propuesto con las apariencias de un "lenguaje sin código ni sintaxis", en definitiva, de un "lenguaje natural", es porque, fundamentalmente, la selección que opera en el mundo visible está absolutamente de acuerdo, en su lógica, con la representación del mundo que se 
impuso en Europa después del quattrocento (Bourdieu, 2003, pp. 135136).

La reflexión de Bourdieu concuerda con las aseveraciones de Goodman acerca de que "El realismo es relativo, es decir, está determinado por el sistema de representación normal para una cultura o una persona concretas en un momento dado" (Goodman, 2010, p. 47). Por lo tanto lo que consideramos como realista tiene que ver con lo que hemos aprendido culturalmente a partir de concepciones arbitrarias de cómo se debe ver representada la realidad, ya sean leyes creadas con la finalidad de explicar la percepción visual, procedimientos técnicos propios del medio de representación utilizado o mismas representaciones ya existentes que por diversos motivos marcan la pauta de "cómo se ven" los objetos.

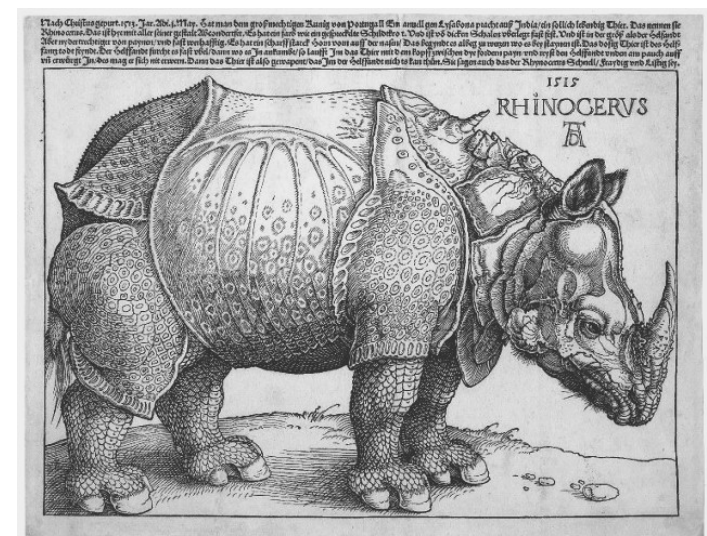

Figura 1. Alberto Durero, Rhinocerus, 1515, xilografía, 24.8 x 31.7 cm. Colección del Museo Británico.

Con respecto a este último punto encontramos el ejemplo que narra Gombrich (1998) sobre la forma en que se 
representó a los rinocerontes durante siglos. En 1515 Durero, quien nunca vio uno real, a partir de un dibujo de alguien más hizo un grabado de un rinoceronte indio con el cuerpo cubierto de gruesas escamas, a la manera de una armadura, interpretando las pronunciadas arrugas del animal como capas que se sobreponen para formar una coraza (Figura 1). Hasta el siglo XVIII, inclusive a otras especies de rinocerontes, se les siguió representando de esa forma en muchos libros de historia natural a pesar de que eran documentos de carácter científico y de que los naturalistas que los dibujaban se supone que los estaban viendo y podían comprobar que su piel no es como una armadura; lo que habla de la enorme influencia que puede ejercer una representación dada sobre las posteriores.

La representación a través de cualquier medio y sobre todo la representación fotográfica, aunque tengan una fuerte conexión denotativa con la realidad, no son una prueba de exactitud y veracidad. Para Sontag (2006, p. 19) "la labor de los fotógrafos no es una excepción genérica a las relaciones a menudo sospechosas entre el arte y la verdad. Aún cuando a los fotógrafos les interese sobre todo reflejar la realidad, siguen siendo acechados por los tácitos imperativos del gusto y la conciencia."

Joan Fontcuberta ha sido una de las personas que, desde el ámbito de la reflexión teórica y desde la producción artística, constantemente ha trabajado con esas relaciones sospechosas; él mismo se ha convertido en sujeto de dudas al escucharlo hablar puesto que hay ciertos momentos en que no se sabe si lo que está diciendo corresponde a sus argumentos teóricos serios o si estamos cayendo en un engaño que forma parte de su nuevo proyecto fotográfico. En su libro El beso de Judas expresa que él no puede confiar en ningún intermediario para ver algo, no en un espejo y mucho menos en la 
fotografía, ya que precisamente el que se le atribuya el estatuto de verdad es lo que le permite mentir más fácilmente. "Contrariamente a lo que la historia nos ha inculcado, la fotografía pertenece al ámbito de la ficción mucho más que al de las evidencias. Fictio es el participio de fingere que significa 'inventar'. La fotografía es pura invención. Toda la fotografía. Sin excepciones" (Fontcuberta, 2015, p. 116).

En 1989 Fontcuberta y Pere Formiguera, otro fotógrafo español, presentaron por primera vez su proyecto Fauna en el Museo de Zoología de Barcelona. La exposición consistió en, precisamente, inventar el archivo de un supuesto zoólogo alemán desaparecido a mediados del siglo XX que catalogó a una serie de animales poco comunes encontrados en diversos viajes. Desde un planteamiento lúdico, los autores propusieron "una reflexión no sólo sobre el realismo y la credibilidad de la imagen fotográfica sino también sobre el discurso científico y el artificio subyacente a todo mecanismo generador de conocimiento, incidiendo sobre la multiplicidad de facetas que afectan a diversas disciplinas de creación" (MACBA, s/f). Las fotografías, los documentos, los audios y los mismos animales disecados que la conformaban, aunado a que fue exhibida en un recinto de carácter científico y que no había ningún tipo de aclaración de que era una propuesta artística, provocaron que muchos de los asistentes creyeran que efectivamente todo lo que estaba ahí era cierto (Figura 2). 


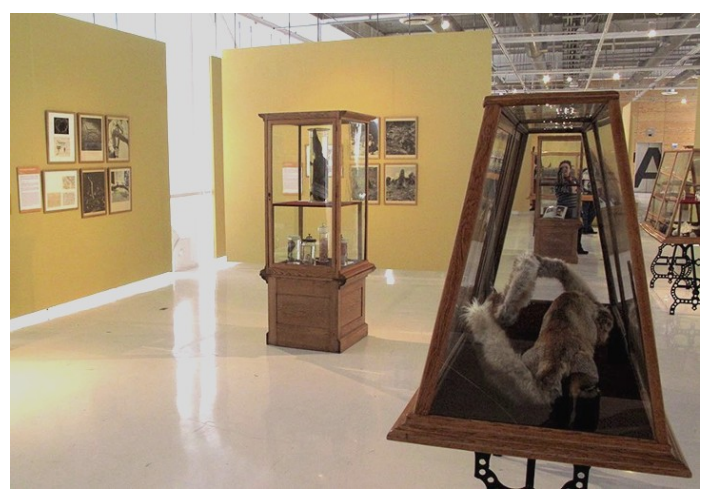

Figura 2. Vista de la exposición Fauna en el Museo del Chopo. Ciudad de México, 2011

Cuando la exposición estuvo en 2011 en el Museo del Chopo de la Ciudad de México -que anteriormente fue un museo de historia natural-, tuve la oportunidad de asistir ver el extenso archivo "perteneciente" al Dr. Ameisenhaufen. En la entrada de la sala estaba una mampara con la narración de Fontuberta y Formiguera acerca de cómo habían encontrado el archivo del doctor y la incredulidad a la que se habían tenido que enfrentar al querer difundir su extraordinario hallazgo, a pesar de tener todas las evidencias fotográficas y documentales en sus manos. El recorrido continuaba con un video en el que, entre otros testimonios, incluían una entrevista con la hermana del zoólogo, para de ahí continuar con un conjunto de vitrinas en las que estaban exhibidos una gran cantidad de objetos de su archivo personal. Lo más sustancioso de la muestra, por supuesto, eran los conjuntos de fotografías que mostraban diversas facetas de los animales: en su hábitat natural, en el laboratorio o en contacto con el doctor (Figura 3); cada conjunto estaba acompañado por la descripción "científica" del animal, además de dibujos, grabaciones, radiografías y, 
en algunos casos, de los animales disecados que había logrado capturar.

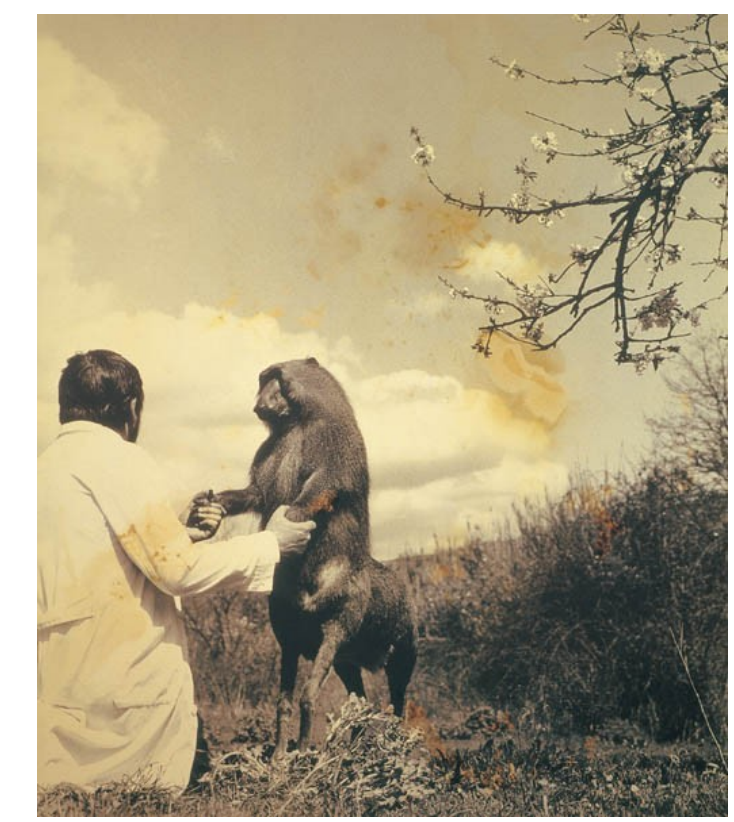

Figura 3. Joan Fontcuberta y Pere Formiguera, Fauna, 1989. Col. del Museo de Arte Contemporáneo de Barcelona

La ficción sí era más fuerte que las supuestas evidencias; los autores no dicen que todo es una mentira pero tampoco lo desmienten, dejan que el espectador sea el que caiga o el que descubra el engaño. Varios visitantes como yo, que además ya conocíamos la trayectoria de Fontcuberta, disfrutamos el juego de ver las supuestas pruebas que demostraban la existencia de esa fauna mítica, pero algunas otras personas, como una familia que estaba recorriendo la exposición al mismo tiempo que yo, que están alejadas del sistema operacional del arte y tienen la concepción de foto- 
grafía como verdad, estaban convencidas y asombradas de la existencia de ese bestiario; aunque era increíble no podían mas que rendirse ante las evidencias y preguntarse en dónde vivirían esos seres.

El crítico y curador de arte Christoph Doswald considera que desde hace tiempo ha habido un ascenso de la ficción dentro de la fotografía, que ha coincidido con su acercamiento al arte, en el que se ha exaltado la abstracción y el artificio tanto en las imágenes de tipo documental como en las manipuladas digitalmente. "La fotografía se da a conocer, 160 años después de su invención, como missing link, como vínculo integrador entre lo artificial y lo real, presuntamente inmediato (Doswald, 2004, p. 222)."

Es así que en la fotografía contemporánea que se produce con fines artísticos se ha disuelto la atadura tan estricta que tenía acerca de ser una representación fidedigna de la realidad, esto no significa que gran parte de las personas hayan dejado de creer en esa idea, pero la certeza que antes existía sobre la veracidad de la imagen ya no es tan contundente puesto que inclusive en ámbitos como el documentalismo, que tradicionalmente se regía por la objetividad, se pueden encontrar ejemplos que abiertamente muestran una interpretación subjetiva de la realidad.

$\mathrm{Si}$ la fotografía funciona ahora como vínculo entre lo artificial y lo real, no es porque antes no lo haya sido, sino porque efectivamente la forma de entender la representación de lo real es convencional y responde a hábitos. Los tiempos han cambiado y ya no podemos ver la fotografía de la misma manera. Dubois lo dice claramente:

En efecto, puesto que de ahora en adelante se negará a la fotografía toda posibilidad de ser simplemente un espejo transparente del mundo, puesto que ya no puede, por esencia, revelar la verdad empírica, veremos desarrollarse diversas actitudes que van todas en el sentido de un desplazamiento de esta capacidad de verdad, de su 
anclaje en la realidad hacia un anclaje en el mensaje mismo: por el trabajo (la codificación) que implica, sobre todo en el plano artístico, la foto se va a convertir en reveladora de la verdad interior (no empírica). Es en el artificio mismo que la foto se volverá verdadera y alcanzará su propia realidad interna. La ficción alcanza e incluso supera la realidad (Dubois, 1986, p. 40).

Para la historiadora de arte Lucy Soutter, en el posmodernismo es que se dejó de tener una fe ciega en la imagen fotográfica y que la fotografía encontró un campo fértil para desarrollar la ficción puesto que una de las ideas del posmodernismo es que la realidad es una construcción y es inestable. "Dentro de este marco teórico, los fotógrafos utilizan su medio no meramente para reflejar una realidad existente, sino más bien para producir un nuevo significado" (Soutter, 2015, p. 52).

Los fotógrafos empezaron a aproximarse a la realidad de un modo distinto, crearon sus propias realidades, desafiaron la lógica y comenzaron a darle más importancia a las ideas que a la técnica; surgió un fuerte interés por resingnificar el mundo a través de la ficción, un recurso que les permitió hablar de lo inexistente, dar su libre interpretación de la realidad, inventar situaciones, personajes y escenarios que podían ser totalmente fantasiosos o, como menciona Soutter, podían ser realistas. "La ficción no se experimenta como una mentira, porque el público reconoce su artificio" (Soutter, 2015, p. 105). Tal es el caso de Fontcuberta que plantea ficciones muy elaboradas y se vale de dispositivos supuestamente confiables que se vuelven verosímiles, pero a la vez son sumamente absurdas y falsas.

Personalmente me interesan mucho ese tipo de representaciones, en las que lo artificial es evidente, particularmente las que recrean a la naturaleza, como la fauna de Fontcuberta. El ser humano siempre ha tratado de apropiarse de la naturaleza y una de las formas en que lo ha 
hecho es construyéndola él mismo, integrándola a su entorno citadino mediante imágenes u objetos que la representan. En las décadas de los 70's estuvieron de moda los fotomurales que cubrían enormes paredes con espectaculares paisajes de lugares remotos: bosques frondosos, selvas de follaje exuberante, montañas nevadas o grandes campos de flores, eran el fondo ideal para decorar la sala y la oficina. O las flores y plantas de tela y plástico que es común encontrar en las casas o negocios, adornando puntos estratégicos para darle "vida" al espacio con sus colores y perenne florecimiento. También están las águilas, flamingos, búhos y los perros de todas las razas que con su cuerpo de yeso o fibra de vidrio esperan en los camellones de las avenidas y en las carreteras a que alguien los compre para llevárselos y tener un animal en la casa.

Pero no sólo en contextos cotidianos encontramos a la naturaleza representada, los museos de historia natural son recintos donde sala tras sala encontramos representaciones de la naturaleza, más sofisticadas y con una mayor pretensión de realismo que las ya ejemplificadas, que en suma presentan un mundo artificial con aspecto natural. Al respecto y retomando la actitud de algunos fotógrafos de aproximarse de una nueva manera a la realidad, podemos encontrar las fotografías de la serie Dioramas que realizó Hiroshi Sugimoto (Figura 4).

Sugimoto relata que cuando llegó a Nueva York se dedicó a visitar los sitios turísticos, entre ellos el Museo Americano de Historia Natural. Los dioramas que presentaban escenas de animales disecados con fondos pintados correspondientes a su hábitat natural le parecían muy falsos, pero al verlos con un ojo cerrado la perspectiva se perdía y la apariencia de los dioramas se volvía muy realista. Entendió que a través de la cámara fotográfica, que ve con un solo ojo, podría hacer que lo artificial se viera real (Dioramas, 
1980). Representaciones de animales y representaciones de paisajes que por medio de una representación fotográfica crean la ilusión de realidad.

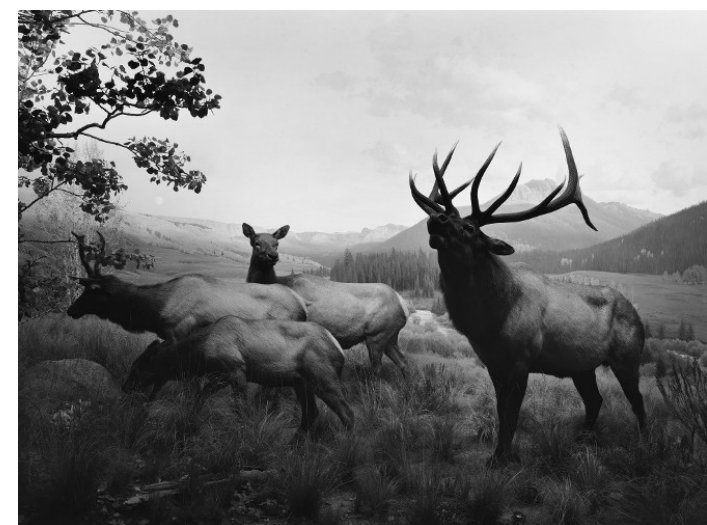

Figura 4. Hiroshi Sugimoto, Wapiti, de la serie Dioramas, 1980, plata s/gelatina. Col. Galería Pace

En el mismo sentido de los animales y los museos, pero con un proceso de trabajo muy distinto, Karen Knorr ha realizado varios proyectos en los que integra ambos elementos en una escena que en la vida real no existiría. En su serie Fábulas (Figura 5) nos muestra salas de museos y otros espacios culturales que han sido tomadas por aves y animales salvajes. Los animales las recorren, reposan sobre el mobiliario y conviven como si fueran dueños de esos lugares, generando imágenes inesperadas y que contradicen lo que sabemos de ese tipo de recintos. Mediante un cuidadoso trabajo análogo y digital en el que fotografía por separado los espacios y los animales, ya sea vivos o disecados, Knorr crea ficciones que reflexionan sobre el hecho de que en los museos los únicos animales que existen son los que están representados en las piezas de arte; 
paradójicamente la verdadera naturaleza y la cultura no son compatibles (Fables, s/f).

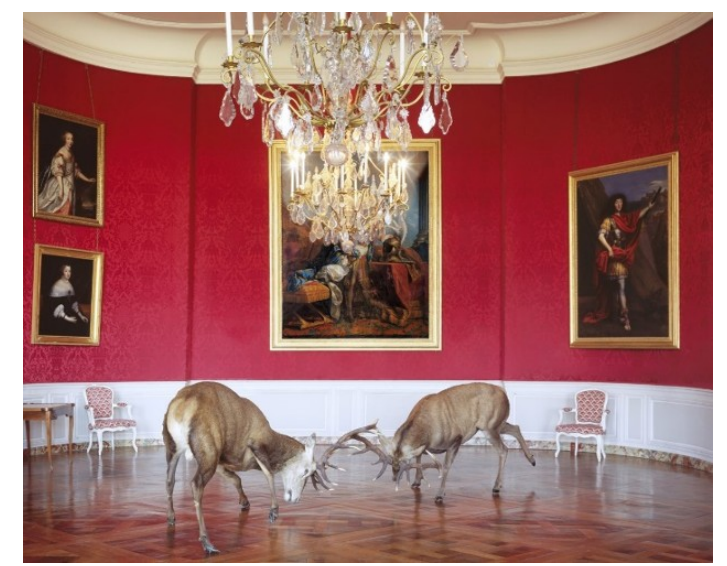

Figura 5. Karen Knorr, The King's reception (Château Chambord), de la serie Fables, 2003-2008, impresión cromógena. Tomada del sitio web de la autora.

Por su parte, Simen Johan también produce una sola imagen a partir de la integración de varias, aunque en su caso la manipulación digital cobra mayor relevancia por la gran cantidad de fotografías que utiliza. Para su serie Until the Kingdom Comes (Fig. 6) viajó por el mundo para fotografiar animales en zoológicos, en reservas naturales y en granjas, así como la diversidad de paisajes que veía. A diferencia de los fotógrafos de naturaleza que muestran a los animales en su entorno y sus comportamientos habituales, Johan los coloca en lugares en los que no corresponden necesariamente, de hecho, en lugares que ni siquiera existen porque él los compone con fragmentos de sus fotografías de distintos países; los mismos animales están retocados digitalmente con la intención de crear escenarios llenos de 
detalles realistas pero que a la vez son idílicos e incongruentes.

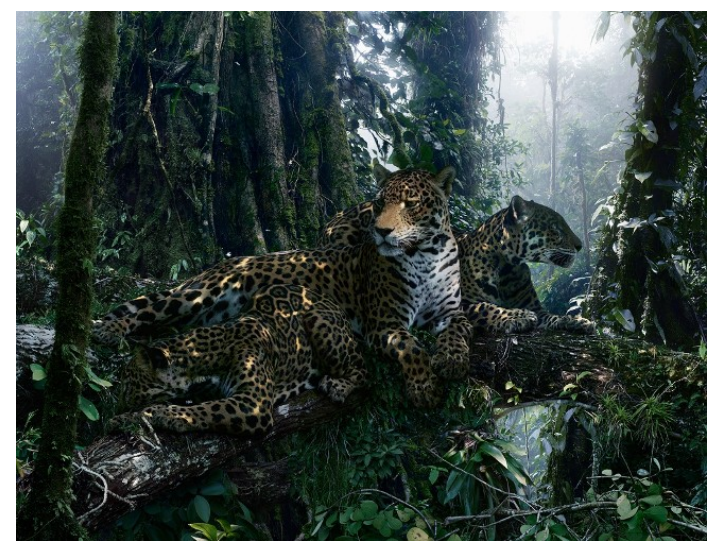

Figura 6. Simen Johan, Untitled \#183, 2015, impresión cromógena digital. Col. Galería Yossi Milo

That seem natural and artificial, for instance, or familiar and otherworldly. I like to create ambiguous images because the world is inherently ambiguous. Our very own existence in this world is simultaneously apparent and unknowable. (..) Reality is a bit like that - things make sense and we take things for granted, but as soon as we start questioning our reality it crumbles and we realise everything is not how it appears (On Post-Production, Pt. 3: Inside the fantastical world of photographer Simen Johan, 27 de enero de 2017).

Otro caso donde el artificio y el mundo real se conjugan está en una de las fotografías con las que Ami Vitale ganó un premio en el World Press Photo, el concurso de fotografía de prensa más importante a nivel internacional; la imagen es de uno de los trabajadores del Centro de Conservación e Investigación del Panda Gigante en China (Figura 7). Haciendo un somero análisis lo primero que vemos representado 
es a un hombre, osos panda y un leopardo; en una segunda lectura vemos que el hombre trae puesto un disfraz de oso panda y lleva un carrito con un leopardo disecado; finalmente observamos que al fondo hay un mural con un paisaje y tres osos pintados. La imagen resultante es una representación de la realidad que Vitale tuvo frente a sus ojos y su cámara, que a su vez muestra tres representaciones distintas, todas hechas con distintos métodos y ninguna con un alto grado de semejanza en relación a su referente. ¿Cuál leopardo se parece más a un leopardo real, el de Ami Vitale o el de Simen Johan? El de él, sin embargo en cuanto a su proceso de producción en su fotografía hay más ficción que en la de ella.

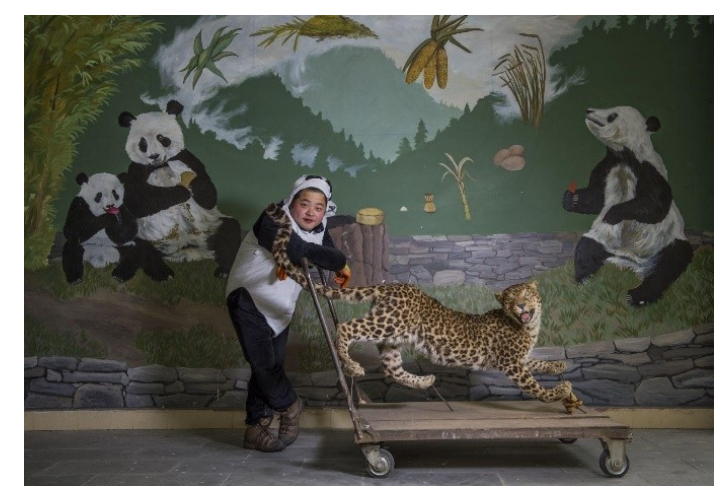

Figura 7. Ami Vitale, Pandas gone wild, 2015. Fotografía comisionada por National Geographic.

Estos autores muestran que en efecto lo natural y lo artificial pueden convivir al mismo tiempo, se pueden generar ficciones que hablen de la realidad y se puede fotografiar una realidad artificial. Los significados y las lecturas que se pueden tener de las fotografías se han 
disparado por el solo hecho de que en una misma imagen pueden haber muchas capas de representación, que por sencillas que parezcan pueden implicar un discurso muy complejo. Sobre todo en la producción fotográfica autoral se ha complejizado la representación, la certeza que antes nos brindaba el creer en la objetividad y la veracidad de lo que veíamos a través de las fotografías se ha disuelto pero esto también le ha otorgado al fotógrafo mayor libertad creativa.

Fontcuberta bien lo señala:

El arte contemporáneo ahonda en esta idea de falsificación como estrategia intelectual. Detrás del juego y la provocación se esconde una sátira sobre el rol que la fotografía debe asumir hoy. ¿Es todavía una tecnología al servicio de la verdad, un soporte de evidencias? Hoy ya nada es evidente; por el contrario, navegamos a través de la nebulosa de la ambigüedad, de espacios virtuales que sustituyen la experiencia (Fontcuberta, 2015, p. 122).

La fotografía, como ese vínculo entre lo real y lo artificial, ha posibilitado acercamientos distintos al mundo, que aunque por un lado supongan una incertidumbre ante lo que vemos, por otro expanden las maneras de entenderlo y conocerlo, permitiendo que el lenguaje de la imagen en el contexto del arte se enriquezca y evolucione constantemente.

\section{REFERENCIAS}

Aspe Armella, V. (2005). Nuevos sentidos de mímesis en la Poética de Aristóteles. Tópicos: Revista de Filosofía, 28, 201234. Recuperado de http://topicosojs.up.edu.mx/ojs/index.php/topicos/articl e/view/232

Bourdieu, P. (2003). Un arte medio. Ensayo sobre los usos sociales de la fotografía. Barcelona: Gustavo Gili. 
Costa, J. (2008). La fotografía creativa. México: Trillas.

Dioramas. (1980). Recuperado de

https://www.sugimotohiroshi.com/new-page-54

Doswald, C. (2004). Missing link - Close the gap!. En D. Pérez

(Ed.), La certeza vulnerable. Cuerpo y fotografía en el siglo XXI.

Barcelona: Gustavo Gili.

Dubois, P. (1986). El acto fotográfico. De la representación a la recepción. Barcelona: Paidós.

Fables. (s/f). Recuperado de

http://karenknorr.com/photography/fables/

Fontcuberta, J. (2015). El beso de Judas. Fotografía y verdad.

Barcelona: Gustavo Gili.

Gombrich, E. H. (1998). Meditaciones sobre un caballo de juguete. Y

otros ensayos sobre la teoría del arte. Madrid: Debate.

Gombrich, E. H. (2008). Arte e ilusión. Estudio sobre la psicología de la representación pictórica. Londres: Phaidon.

Gombrich, E. H., Hochberg, J. y Black, M. (1973). Arte, percepción y realidad. Barcelona: Paidós.

Goodman, N. (2010). Los lenguajes del arte. Aproximación a la teoría de los simbolos. Madrid: Paidós.

González Ochoa, C. (2005). Apuntes acerca de la representación.

México, D.F.: UNAM.

MACBA. (s/f). Fauna. Sitio web del Museo de Arte Contemporáneo de Barcelona. Recuperado de https://www.macba.cat/es/fauna-1659

On Post-Production, Pt. 3: Inside the fantastical world of photographer Simen Johan. (27 de enero de 2017). British Journal of Photography. Recuperado de https://www.bjponline.com/2017/01/on-post-production-pt-3-insidethe-fantastical-world-of-photographer-simen-johan/.

Real Academia Española (2014). Diccionario de la lengua española (23a ed.) |versión 23.2 en líneal. Recuperado de https://dle.rae.es 
Sontag, S. (2006). Sobre la fotografía. México, D.F.: Alfaguara.

Soutter, L. (2015). ¿Por qué fotografía artística?. Salamanca:

Universidad de Salamanca.

Wright, T. (2001). Manual de fotografía. Madrid: Akal.

\section{ACERCA DE LA AUTORA}

Lucía Castañeda Garma (lcgarma@hotmail.com) es licenciada en Comunicación Medios Masivos en la Universidad Autónoma de Aguascalientes. Actualmente estudia la Maestría en Artes Visuales en el Programa de Posgrados de la Facultad de Artes y Diseño de la UNAM. Cuenta con siete exposiciones individuales distintas y ha participado en varias exposiciones colectivas. Su obra ha sido seleccionada y premiada en algunos concursos nacionales. Actualmente se desempeña como docente de fotografía a nivel universitario y como fotógrafa independiente (ORCID 0000-0001-9384-5149).

Recibido: 11/02/2019

Aceptado: 03/04/2019

CÓMO CITAR ESTE ARTÍCULO

Castañeda Garma, L. (2020). La falsa realidad. Reflexiones sobre la representación. Caleidoscopio - Revista Semestral de Ciencias Sociales y Humanidades, 23(42), 177-203.

doi: $10.33064 / 42 \operatorname{crscsh} 2157$ 